\title{
Alternatives to standard acute in-patient care in England: short-term clinical outcomes and cost-effectiveness
}

M. Slade, S. Byford, B. Barrett, B. Lloyd-Evans, H. Gilburt, D. P. J. Osborn, R. Skinner,

M. Leese, G. Thornicroft and S. Johnson

\section{Background}

Outcomes following admission to residential alternatives to standard in-patient mental health services are underresearched.

\section{Aims}

To explore short-term outcomes and costs of admission to alternative and standard services.

\section{Method}

Health of the Nation Outcome Scales (HoNOS), Threshold Assessment Grid (TAG), Global Assessment of Functioning (GAF) and admission cost data were collected for six alternative services and six standard services.

\section{Results}

All outcomes improved during admission for both types of service $(n=433)$. Adjusted improvement was greater for standard services in scores on HoNOS (difference 1.99, 95\% Cl 1.12-2.86), TAG (difference 1.40, 95\% Cl 0.39-2.51) and GAF functioning (difference $4.15,95 \% \mathrm{Cl} 1.08-7.22$ ) but not GAF symptoms. Admissions to alternatives were 20.6 days shorter, and hence cheaper (UK£3832 v. £9850). Standard services cost an additional £2939 per unit HoNOS improvement.

\section{Conclusions}

The absence of clear-cut advantage for either type of service highlights the importance of the subjective experience and longer-term costs.

\section{Declaration of interest}

None.
Admission to standard hospital-based mental health services is the established response to a crisis in mental health, yet little is known about the resulting impact on risk and on health and social needs. ${ }^{1}$ What is clear is that traditional in-patient services are unpopular with many people who use them, ${ }^{2}$ leading to a call for alternatives to be available. ${ }^{3}$ However, the optimal balance between provision of standard and residential alternatives to in-patient mental health services remains uncertain. A recent systematic review identified no high-quality randomised controlled trial evidence in relation to residential alternatives to in-patient services, with preliminary evidence indicating that community-based alternatives may be feasible and more acceptable to people who would otherwise need admission. ${ }^{4}$ In this observational study we sought to understand and compare the short-term outcomes and costs associated with receiving care from residential alternatives to in-patient services.

\section{Method}

An observational cohort study was conducted in 12 services. Six services providing a residential alternative to standard in-patient services were chosen as examplars of the typology of services identified in the first phase of the Alternatives Study: ${ }^{5}$ they included a clinical crisis house, a short-stay ward, a crisis team beds service and two non-clinical alternatives. A comparison standard acute ward for each alternative service was identified which accepted patients from a similar catchment area and was where possible served by the same community mental health services as the chosen alternative services. The characteristics of the services are described elsewhere in this supplement. ${ }^{6}$

\section{Sample}

The target sample comprised 35-40 consecutively admitted patients at each site. Exclusion criteria were opting out of the study, being admitted for non-crisis purposes (e.g. planned respite care) and being transferred from another acute ward for non-clinical reasons.

\section{Measures}

The Health of the Nation Outcome Scales (HoNOS) is a 12-item staff-rated measure of social disability. ${ }^{7}$ Each item is scored from 0 (no problem) to 4 (severe to very severe problem), and the HoNOS score is the sum of the item scores (range 0-48, low score better). The Global Assessment of Functioning (GAF) is a twoitem staff-rated measure of symptoms and social functioning; each item is scored from 1 (most severe) to 90 (no problems). ${ }^{8}$ The Threshold Assessment Grid (TAG) is a seven-item staff-rated measure of severity of mental health problems, across domains of need, safety and risk. ${ }^{9}$ Four items are scored from 0 (none) to 3 (severe), and the remaining three items can also be scored as 4 (very severe). The TAG score is the sum of the item scores (range 0-24, low score better).

\section{Procedures}

A consecutive series of participants were recruited to the study on admission to each service. All participants received information through posters displayed on the unit and information sheets received on admission and at discharge, and were given the opportunity to opt out. Clinical staff received researcher-led training to rate the measures, and completed the assessments as soon as possible after the participant's admission. Participants were rated again at discharge, by the same member of staff where possible. The manager of each alternative service provided budget data for the service to calculate cost per bed-day. The cost of each standard ward was taken from nationally available estimates. ${ }^{10}$ 


\section{Statistical analysis}

Baseline values and changes for each of the outcomes were calculated and presented for each service, and $t$-tests and Wilcoxon tests used to compare lengths of stay. Mean differences between the standard and alternative admissions at follow-up, adjusted for area and baseline level only and also for possible confounding factors, were estimated from linear regression models, one for each outcome of interest. Choice of possible confounders was informed by results from a previous paper in this series, ${ }^{6}$ which identified predictors of being admitted to an alternative rather than a standard service. Service was included as a clustering variable and robust standard errors computed. Area was included as a fixed effect, and analyses were repeated excluding the single non-paired site as a sensitivity analysis. A logistic regression was also performed with the binary dependent variable a clinically significant change of at least 7 points in HoNOS score, ${ }^{11}$ and proportions improving in the two types of service were estimated from this model (adjusting for area and baseline level). Multiple imputation was used for missing values (these were mainly for the predictor variables, about $13 \%$ of the total).

The total cost of the stay in the initial alternative or standard service was calculated and differences in the cost of standard and alternative admissions (adjusted for baseline predictors) compared using standard parametric tests with bootstrapped analyses carried out to address skewed cost distributions. Costs were then linked to outcomes using an incremental cost-effectiveness analysis to explore the relationship between cost and HoNOS score. The probability that alternative facilities are more cost-effective than standard services was then explored through the calculation of cost-effectiveness acceptability curves, which show the probability that admission to an alternative service is more cost-effective than admission to a standard ward for different values that a decision-maker might be willing to pay for improvements in the HoNOS outcome. ${ }^{12}$

\section{Results}

During the study period 467 patients were admitted, and baseline outcome measures data were collected for 433 participants (93\%).
The characteristics of participants are shown in Table 1. Outcome data at discharge were collected for 397 patients (92\%). Initial analysis indicated that the profile of patients admitted to the Tidal Model ward, and their length of stay and subsequent outcomes (as well as content of care provided), ${ }^{13}$ were similar to the profiles for standard in-patient services. Therefore Tidal Model data are presented separately in Table 1, and the remainder of the results use data from the five other alternative services and six standard services only. The mean admission and discharge ratings for the Tidal Model ward $(n=35)$ were GAF symptoms $45.2($ s.d. $=20.7)$ improving to 62.3 (s.d.=23.2); GAF functioning 60.6 (s.d.=18.2) improving to 71.7 (s.d. $=19.6$ ); TAG 6.8 (s.d. $=3.7$ ) improving to 3.7 (s.d.=2.9); and HoNOS 12.0 (s.d.=4.4) improving to 8.5 (s.d. $=6.6)$.

The length and costs of admissions are shown in Table 2. Admissions to alternative services were 20.6 days shorter on average than those to standard services (mean 17.6 days $v$. 38.2 days, 95\% CI 12.64-28.56, $P<0.001$; median 11 v. 19.5, $P<0.001$, Wilcoxon test) and significantly cheaper ( $£ 3832 \mathrm{v}$. \{9850, $P=0.025)$. Admission scores on the four outcome measures are shown in Table 3. At discharge, outcomes were in the direction of improvement on every measure (Table 4).

Using a seven-point change in HoNOS rating as indicating reliable and clinically significant change, ${ }^{11} 38$ (22\%) of 176 patients in alternative services improved, as did $92(41 \%)$ of 222 in standard services (difference 19\%, 95\% CI 11-29, $P<0.001$ ). The proportions estimated from logistic regression, adjusting for baseline level and area, were $17 \%$ and $33 \%$ respectively (difference $16 \%, 95 \%$ CI $13-18, P<0.001)$.

There were significant differences at the aggregated level, comparing all alternatives with all standard services, in favour of standard services (Table 5). Some (although not all) of the relative improvement in the standard services could be attributed to baseline predictors, since the effect sizes reduced when these were controlled for. For TAG and HoNOS scores these differences remained statistically significant even after controlling for predictors. For GAF symptoms the evidence was less clear, since the difference for

\begin{tabular}{|c|c|c|c|c|}
\hline & $\begin{array}{l}\text { Alternatives minus } \\
\text { Tidal Model ward }\end{array}$ & $\begin{array}{l}\text { Tidal Model } \\
\text { ward }\end{array}$ & $\begin{array}{l}\text { Standard } \\
\text { services }\end{array}$ & $\begin{array}{l}\text { Whole } \\
\text { sample }\end{array}$ \\
\hline Number of services & 5 & 1 & 6 & 12 \\
\hline Number of patients & 176 & 35 & 222 & 433 \\
\hline Male gender, $n(\%)$ & $86(49)$ & $11(31)$ & $120(54)$ & $217(50)$ \\
\hline Age, years: mean (s.d.) & $42.2(13.3)$ & 42.5 (11.9) & $39.4(12.9)$ & $40.1(13.0)$ \\
\hline \multicolumn{5}{|l|}{ Marital status, $n(\%)$} \\
\hline Unmarried & $101(57)$ & $15(43)$ & $113(54)$ & $229(55)$ \\
\hline Married/cohabiting & $27(21)$ & $9(26)$ & $64(31)$ & $110(26)$ \\
\hline Separated/divorced & $36(21)$ & $9(26)$ & $26(12)$ & $71(17)$ \\
\hline \multicolumn{5}{|l|}{ Ethnicity, $n$ (\%) } \\
\hline White British & $120(68)$ & $24(71)$ & $159(72)$ & $303(70)$ \\
\hline Caribbean & $23(13)$ & $3(9)$ & $8(4)$ & $34(8)$ \\
\hline African & $12(7)$ & $1(3)$ & $8(4)$ & $21(5)$ \\
\hline Born in UK, $n(\%)$ & $149(85)$ & $23(85)$ & $170(81)$ & $342(83)$ \\
\hline \multicolumn{5}{|l|}{ Time since first contact with mental health services, $n(\%)$} \\
\hline Less than 2 years & $54(31)$ & $13(41)$ & $86(41)$ & $151(37)$ \\
\hline $2-5$ years & $30(18)$ & $5(16)$ & $37(18)$ & $72(18)$ \\
\hline More than 5 years & $84(51)$ & $14(44)$ & $83(40)$ & $181(45)$ \\
\hline Contact with mental health services in 3 months preceding admission, $n$ (\%) & $125(71)$ & $26(74)$ & $128(58)$ & $279(64)$ \\
\hline \multicolumn{5}{|l|}{ Symptoms or diagnosis, $n$ (\%) } \\
\hline Psychosis & $54(31)$ & $11(31)$ & $103(46)$ & $168(39)$ \\
\hline Depression & $71(40)$ & $11(31)$ & $63(28)$ & $145(34)$ \\
\hline Patient initiated help-seeking, $n(\%)$ & $53(30)$ & $4(11)$ & $36(17)$ & $93(22)$ \\
\hline Cooperative in admissions procedure, $n(\%)$ & $154(92)$ & $25(71)$ & $166(77)$ & $345(83)$ \\
\hline Length of stay, days: mean (s.d.) & $17.5(27.6)$ & $32.0(31.2)$ & $38.2(47.7)$ & $29.2(40.6)$ \\
\hline
\end{tabular}




\begin{tabular}{|c|c|c|c|}
\hline & $\begin{array}{c}\text { Patients } \\
n\end{array}$ & $\begin{array}{l}\text { Length of stay, days } \\
\text { Mean (s.d.) }\end{array}$ & $\begin{array}{c}\text { Cost of admission, UKf } \\
\text { Mean (s.d.) }\end{array}$ \\
\hline Crisis team beds & 35 & $7.1(5.3)$ & 657 (489) \\
\hline Crisis team beds comparison & 34 & $50.4(68.4)$ & $13011(17645)$ \\
\hline Short-stay ward & 40 & $1.2(0.5)$ & $292(126)$ \\
\hline Short-stay ward comparison & 37 & $23.6(32.4)$ & $6080(8352)$ \\
\hline Clinical crisis house & 31 & $53.9(49.1)$ & $13633(12400)$ \\
\hline Clinical crisis house comparison & 37 & $36.4(43.3)$ & 9379 (11180) \\
\hline Non-clinical alternative 1 & 35 & $16.4(6.5)$ & $3466(1374)$ \\
\hline Non-clinical alternative 1 comparison & 39 & $44.3(48.2)$ & $11422(12443)$ \\
\hline Non-clinical alternative 2 (Black ethnicity focus) & 35 & $15.6(8.1)$ & $2737(1412)$ \\
\hline Non-clinical alternative 2 comparison & 35 & $43.1(55.5)$ & $11131(14330)$ \\
\hline Tidal model ward comparison & 39 & $32.5(27.8)$ & 8395 (7167) \\
\hline All five alternative services & 176 & $17.6(27.5)$ & 3832 (7023) \\
\hline All six comparisons & 221 & $38.2(47.7)$ & 9850 (12316) \\
\hline
\end{tabular}

\begin{tabular}{|c|c|c|c|c|c|}
\hline & Patients, $n$ & GAF symptoms & GAF functioning & TAG & HONOS \\
\hline Crisis team beds & 35 & $50.3(13.6)$ & $55.2(18.9)$ & $7.23 .4)$ & $12.8(5.8)$ \\
\hline Crisis team beds comparison & 34 & $45.9(19.6)$ & $60.1(19.8)$ & $7.3(3.4)$ & $12.8(5.8)$ \\
\hline Short-stay ward & 40 & $54.2(19.1)$ & $63.1(16.5)$ & $5.8(2.7)$ & $11.2(5.3)$ \\
\hline Short-stay ward comparison & 37 & $35.8(14.1)$ & $51.8(18.2)$ & $10.2(3.1)$ & $16.1(4.5)$ \\
\hline Clinical crisis house & 31 & $57.1(20.7)$ & $58.0(21.8)$ & $4.7(2.9)$ & $9.2(4.0)$ \\
\hline Clinical crisis house comparison & 37 & $57.5(21.1)$ & $66.3(13.9)$ & $5.0(2.8)$ & $10.0(4.7)$ \\
\hline Non-clinical alternative 1 & 35 & $57.1(14.8)$ & $58.6(14.8)$ & $7.2(3.2)$ & $13.1(5.5)$ \\
\hline Non-clinical alternative 1 comparison & 39 & $45.6(17.8)$ & $57.7(20.9)$ & $7.6(2.9)$ & $13.1(4.4)$ \\
\hline Non-clinical alternative 2 (Black ethnicity focus) & 35 & $56.9(18.0)$ & $63.8(16.2)$ & $6.9(3.3)$ & $11.8(5.3)$ \\
\hline Non-clinical alternative 2 comparison & 35 & $47.2(24.5)$ & $59.5(21.1)$ & $6.0(3.1)$ & $12.2(6.1)$ \\
\hline Tidal Model ward comparison & 39 & $56.1(16.4)$ & $63.6(16.7)$ & $5.6(3.8)$ & $11.4(5.6)$ \\
\hline All five alternative services & 176 & $55.1(17.4)$ & $55.1(17.4)$ & $6.4(3.2)$ & $11.7(5.4)$ \\
\hline All six comparisons & 221 & $48.1(20.3)$ & $60.0(19.0)$ & $6.9(3.6)$ & $12.6(5.6)$ \\
\hline
\end{tabular}

\begin{tabular}{|c|c|c|c|c|c|}
\hline & Patients, $n$ & GAF symptoms & GAF functioning ${ }^{a}$ & $\mathrm{TAG}^{\mathrm{b}}$ & HONOS $^{b}$ \\
\hline Crisis team beds & 35 & $9.1(12.7)$ & $6.6(19.5$ & $-1.9(3.5)$ & $-2.3(5.3)$ \\
\hline Crisis team beds comparison & 34 & $22.7(23.3)$ & $12.2(13.6)$ & $-3.1(3.4)$ & $-5.8(6.0)$ \\
\hline Short-stay ward & 40 & $12.5(15.9)$ & $7.3(16.3)$ & $-1.5(2.1)$ & $-0.9(4.2)$ \\
\hline Short-stay ward comparison & 37 & $23.3(18.3)$ & $8.9(16.6)$ & $-3.5(2.7)$ & $-6.6(4.2)$ \\
\hline Clinical crisis house & 31 & $10.4(23.6)$ & $3.4(15.0)$ & $-0.4(3.7)$ & $0.1(6.4)$ \\
\hline Clinical crisis house comparison & 37 & $14.5(23.9)$ & $6.3(18.4)$ & $-2.2(3.5)$ & $-2.3(7.3)$ \\
\hline Non-clinical alternative 1 & 35 & $6.1(16.2)$ & $7.1(21.2)$ & $-1.5(3.8)$ & $-2.9(6.2)$ \\
\hline Non-clinical alternative 1 comparison & 39 & $18.4(19.2)$ & $11.3(15.7)$ & $-3.7(3.5)$ & $-5.1(4.6)$ \\
\hline Non-clinical alternative 2 (Black ethnicity focus) & 35 & $9.2(18.4)$ & $4.3(11.8)$ & $-0.9(3.2)$ & $-2.8(4.0)$ \\
\hline Non-clinical alternative 2 comparison & 35 & $26.4(27.6)$ & $14.7(19.5)$ & $-3.2(2.6)$ & $-6.5(6.2)$ \\
\hline Tidal Model ward comparison & 39 & $20.5(16.9)$ & $11.8(18.0)$ & $-2.8(3.7)$ & $-4.6(6.8)$ \\
\hline All five alternative services & 176 & $9.5(17.5)$ & $5.9(17.0)$ & $-1.3(3.3)$ & $-2.2(5.3)$ \\
\hline All six comparisons & 221 & $20.9(21.8)$ & $10.8(17.1)$ & $-3.1(3.3)$ & $-5.1(6.1)$ \\
\hline
\end{tabular}

this outcome only remained significant at the 0.05 level in the imputed data after adjustment. Overall, admissions to the standard services were more costly than the alternative services, but were associated with better outcomes. Incremental cost-effectiveness analysis indicated that the standard services cost an additional $£ 2939$ per unit improvement in HoNOS score. To inform decision-making about the additional cost of admission to standard services and the additional improvements in outcome, the costeffectiveness acceptability curve (Fig. 1) shows the probability that admission to the standard services is more cost-effective than admission to alternative services for different values that a decision-maker might be willing to pay for improvements in outcomes.

If there is no willingness to pay anything for an improvement in HoNOS score, the probability that admission to standard services is more cost-effective than admission to standard services is zero. As the value placed on the willingness to pay for improvements in HoNOS score rises, the probability that admission to 


\begin{tabular}{|c|c|c|c|c|c|c|c|c|c|}
\hline & \multicolumn{3}{|c|}{$\begin{array}{l}\text { Controlling for baseline and area only } \\
\qquad \text { (maximum } n=340 \text { ) }\end{array}$} & \multicolumn{3}{|c|}{$\begin{array}{l}\text { Controlling for baseline, area } \\
\text { and individual characteristics }{ }^{\text {a }} \\
\text { (maximum } n=339 \text { ) }\end{array}$} & \multicolumn{3}{|c|}{$\begin{array}{c}\text { Controlling for baseline, area and individual } \\
\text { characteristics }{ }^{\text {a, }} \text { after imputation of missing } \\
\text { values }(n=398)\end{array}$} \\
\hline & Difference & $95 \% \mathrm{Cl}$ & $P$ & Difference & $95 \% \mathrm{Cl}$ & $P$ & Difference & $95 \% \mathrm{Cl}$ & $P$ \\
\hline GAF symptoms ${ }^{b}$ & 5.588 & 2.107 to 9.069 & 0.005 & 3.142 & -0.651 to 6.934 & 0.095 & 4.327 & 0.722 to 7.932 & 0.023 \\
\hline GAF functioning ${ }^{\mathrm{b}}$ & 4.579 & 0.797 to 8.361 & 0.022 & 4.150 & 1.080 to 7.219 & 0.013 & 4.183 & 0.522 to 7.843 & 0.029 \\
\hline $\mathrm{TAG}^{\mathrm{C}}$ & -1.375 & $\begin{array}{c}-2.165 \\
\text { to }-0.586\end{array}$ & 0.003 & -1.403 & $\begin{array}{c}-2.511 \\
\text { to }-0.295\end{array}$ & 0.018 & -1.356 & $\begin{array}{c}-2.574 \\
\text { to }-0.139\end{array}$ & 0.032 \\
\hline HONOS $^{\mathrm{C}}$ & -1.657 & $\begin{array}{l}-3.184 \\
\text { to }-1.657\end{array}$ & $<0.001$ & -1.993 & $\begin{array}{l}-2.859 \\
\text { to }-1.126\end{array}$ & $<0.001$ & -2.196 & $\begin{array}{l}-3.176 \\
\text { to }-1.216\end{array}$ & 0.001 \\
\hline
\end{tabular}

standard services is more cost-effective also rises to a maximum of just under $100 \%$. Standard services have a greater probability of being the more cost-effective option at levels of willingness to

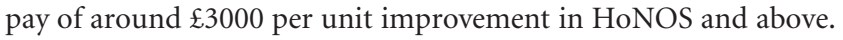

\section{Discussion}

Measures of outcome consistently improved in a series of admission cohorts admitted to both standard in-patient wards and residential alternatives to in-patient services. The improvement over an admission was larger for the cohorts admitted to standard services, especially for HoNOS and TAG. Admissions to standard services were in general longer, and therefore more expensive. The likelihood of an admission to a standard service being the more cost-effective option in relation to HoNOS improvement reached $50 \%$ at values of willingness to pay for a one-point improvement in HoNOS score of around $\mathfrak{E} 3000$. These results can be understood at both the patient and the service level.

\section{Implications for patients}

In relation to patient care, outcomes improved in both classes of service. The improvement was larger in the standard services, and equivalent to reductions from admission (mean score 14.3) to

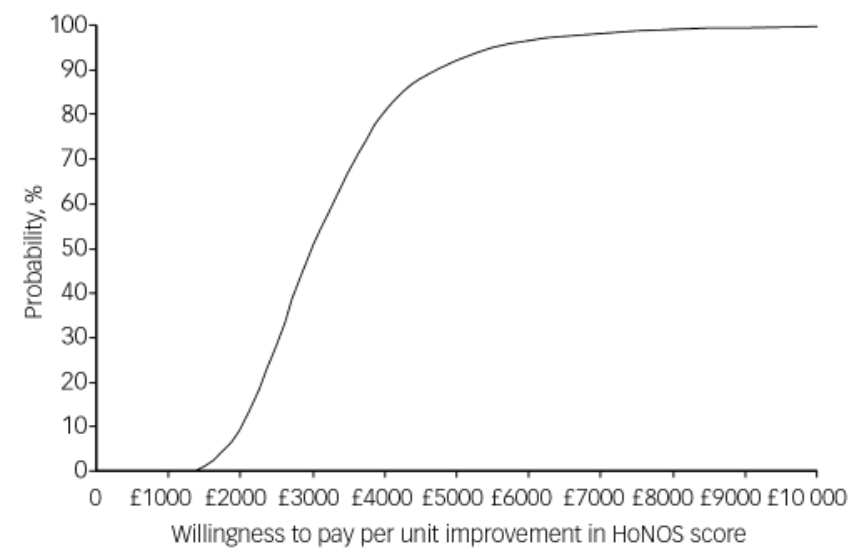

Fig. 1 Cost-effectiveness acceptability curve showing the probability that admission to standard services is cost-effective for different values that a decision-maker is willing to pay for a one-point improvement in Health of the Nation Outcome Scales (HoNOS) score. discharge (mean score 7.2) in the largest HoNOS outcomes database $(n=101820)$, generated through routine outcome collection in Australia. ${ }^{14}$ There are at least three possible reasons for the greater improvement in HoNOS ratings for standard admissions. First, standard services may be more effective than alternative services in addressing the domains of health and social functioning specifically assessed with HoNOS. However, the difference after adjustment was of only marginal clinical importance: 2.0 points on HoNOS and 1.4 points on TAG. Second, the admission HoNOS score for alternative services was either equal to (nonclinical alternative 1 only) or lower than the comparison standard service. A similar pattern was evident for TAG, although less so for GAF. A proportionally similar improvement in outcome across both classes of service would therefore lead to a greater absolute improvement in standard services, and preliminary emerging evidence of proportional rather than absolute change in different subpopulations suggests this possibility might warrant further consideration. ${ }^{15}$

Finally, the length of stay was longer at standard services (mean 38.2 days) than at alternative services (mean 17.6 days). There was a complex relationship between length of stay and outcome improvement across the four outcomes and 12 services, but no consistent relationship between length of stay and outcome at the patient level, despite this finding at the aggregate level. Therefore length of stay was not included as a confounder. This leaves open the possibility that the greater improvement in HoNOS score was partly or wholly attributable for some patients to the longer duration of stay associated with admission to a standard service. Our data cannot directly address this possibility, but the pattern for some patients in alternative services of very short stay and relatively limited improvement raises questions about whether they are discharged prematurely (and longer stays would lead to improved outcome) or whether they are rapidly assessed as unsuitable for or not requiring the service and transferred to a standard ward (or discharged).

\section{Service-level implications}

The shorter length of stay in alternative services means that (assuming 100\% bed occupancy) they can offer 2.2 times the admissions per bed that is possible in standard services. Although it is tempting to link throughput data with the number of HoNOS improvers to arrive at an overall cost-effectiveness measure for alternative compared with standard services, this is not appropriate for three reasons. First, the study was an observational design, and the choice of where to admit an individual was not random. People admitted to alternatives were more likely to be 
known to services, ${ }^{6}$ and so the two classes of service are working with different, albeit overlapping, groups. If people admitted to alternatives service are on average less acutely ill (i.e. have more chronic symptoms and social disability with occasional exacerbation to a point requiring admission) then this raises the question of whether measures such as HoNOS are the best outcome for evaluating the effectiveness of admission. Second, staff ratings were made by a mixed group of workers in the alternative services, not all of whom had a formal mental health training. It is possible that, despite the provision of training for all staff raters, clinicians in standard services were better trained to detect changes in the domains assessed in HoNOS. Finally, it is not possible to know whether standard services would achieve the same gains in outcome using shorter admissions, and hence more efficient use of beds, or indeed whether alternative services would achieve greater gains using longer admissions. One approach evaluated in Scotland was to close a ward and use the resulting resources to fund a marginal increase in beds available on other wards and increased staff in community services. ${ }^{16}$ No difference was found in post-closure rates of admission to other wards, bed occupancy, number of incidents, number of days the ward doors were locked, observation levels, sickness levels or number of temporary staff used.

\section{Limitations and future research}

Alternative services now comprise $10 \%$ of the overall in-patient provision, ${ }^{9}$ but this growth has been unevaluated and uncoordinated. Our observational study demonstrates that in relation to short-term clinical outcomes, and consistent with other studies, ${ }^{17}$ clinical improvement occurs in both classes of service. Without more experimental designs it is not possible to make definitive statements about relative and absolute cost-effectiveness. For example, randomisation of the subgroup of patients who are served by both classes of service to either an alternative or a standard admission would allow comparative effectiveness to be established. ${ }^{6}$ Barriers to a randomised controlled trial include lack of fidelity scales for the identified types of alternative service and for what constitutes a 'standard' in-patient service, lack of consensus in relation to evaluation strategies, and the likely requirement for substantial resourcing to both run and evaluate several services, which in turn raises questions about generalisability. ${ }^{18}$

A more feasible short-term research strategy would be to identify and amplify the active and positive ingredients of in-patient services. There is no consensus on the ideal in-patient service model, and there is great variation in even the most basic service planning decisions. For example, the most recent survey of in-patient care in England identified that the numbers of beds per ward ranged from 5 to $32 .{ }^{19}$ A complex relationship between service type and content of care provided was also found in this study, ${ }^{13}$ a finding replicated in relation to service type and satisfaction and the experience of services. ${ }^{20,21}$ Experimental intervention to systematically vary potential active ingredients of care will allow the development of testable models, which can then be investigated using established methods for evaluating complex interventions. ${ }^{22}$ It is plausible that the concept of an alternative service may prove to be a proxy measure for a constellation of features, such as more patient choice and control, less coercion, more motivated staff, less staff-patient social distance, community-based care and the provision of specific types of intervention. A more detailed understanding of these components and their effectiveness may over time lead to the abandonment of the binary alternative $v$. standard service distinction, in favour of a more sophisticated understanding of the impact of each feature for individual patients. ${ }^{23}$
A specific research question relates to the impact of different lengths of stay. As part of the wider study, we undertook stakeholder interviews (primarily reported elsewhere). ${ }^{6}$ These revealed a number of influences on length of stay: alternatives often had strong links with local crisis resolution teams - for which there is an emerging evidence base ${ }^{24}$ - or had their own aftercare services, and these more robust community aftercare arrangements facilitated earlier discharge; standard services had more standardised discharge procedures, some of which (such as waiting until the next weekly ward round) delayed discharge; patients admitted to standard services presented on average more risk issues, leading to greater caution in discharge decision-making. Keeping lengths of stay equal in the two classes of service would allow a direct comparison of effectiveness, but for some services (e.g. the short-stay ward) this would not be possible, and for others it would be problematic for the reasons shown in the stakeholder interviews. ${ }^{6}$ A repeated measures design, for example using routinely collected outcome data, ${ }^{25}$ would allow investigation of the extent to which outcomes improve continually during an admission, or whether there is a plateau after a certain length of time. This would inform guidelines about the ideal length of admission.

A final research strategy involves more systematic exploration of trade-offs between different desirable dimensions of evaluation. Service provision is not all about outcome. For example, it is known that rates of detention are higher for people from Black and minority ethnic (BME) communities: $38 \%$ compared with $19 \%$ among people from non-BME communities. ${ }^{26}$ The rationale for the BME-focused service investigated in our study was not to generate improved outcome but to offer a more culturally sensitive experience of admission. The relative weighting placed on accessibility, satisfaction, effectiveness, cost-effectiveness and efficiency is a sociopolitical not a clinical decision. The contribution research can make is to inform the debate, and identify the implications of different weightings.

Avoiding the need for hospitalisation is desirable, and crisis resolution teams which provide intensive support leading to reduced admission rates are now widespread in England. ${ }^{27,28}$ Where admission is necessary, we found that people are likely to improve in relation to short-term clinical outcomes whether admitted to an alternative or a standard service, with higher improvement (but of marginal clinical importance) in standard services. Our costing approach used a narrow perspective, only including the costs of the admission. A key question is what happens following discharge in terms of longer-term outcomes and costs. In a separate paper we provide preliminary evidence regarding longer-term costs following admission to the two types of service. ${ }^{29}$ There was little difference in the use and cost of subsequent admissions or other hospital and community mental health services between people initially admitted to traditional or to alternative services. Hence the shorter lengths of stay in alternative services were not associated with a greater need for subsequent admissions or support from other mental health services, and led to significantly lower 12 -month total costs for service use.

It is known that the experience of admission is central. Satisfaction associated with an involuntary admission predicts 1 -year involuntary readmission rates, ${ }^{30}$ yet in 2008 the Mental Health Act Commission found that standard wards 'appear to be tougher and scarier places than we saw a decade ago., ${ }^{31}$ Recent calls from professionals and consumers, ${ }^{32,33}$ and emerging policy guidance, ${ }^{34}$ have all emphasised the need for more focus within in-patient services on 'putting a greater focus on the individual and care that is personalised. ${ }^{35}$ Our empirical finding was that there is no substantial difference in short-term staff-rated 
outcomes - the largest change was in HoNOS scores (an adjusted difference of 2 on a scale ranging from 0 to 48), with less clear-cut advantages for the other three outcome measures. This provides a further argument for ensuring that service users' preferences and experiences should strongly inform clinical decision-making.

Mike Slade, PhD, Sarah Byford, PhD, Barbara Barrett, MSC, Health Service and Population Research Department, Institute of Psychiatry, King's College London; Brynmor Lloyd-Evans, PhD, Department of Mental Health Sciences, University College London; Helen Gilburt, PhD, Health Service and Population Research Department, Institute of Psychiatry, King's College London; David P. J. Osborn, PhD, Department of Mental Health Sciences, University College London; Rachel Skinner MA, Morven Leese, PhD, Graham Thornicroft, PhD, Health Service and Population Research Department, Institute of Psychiatry, King's College London; Sonia Johnson DM, Department of Mental Health Sciences, University College London, London, UK

Correspondence: Dr Mike Slade, Health Service and Population Research Department, Box PO29, Institute of Psychiatry, King's College London, De Crespigny Park, Denmark Hill, London SE5 8AF, UK. Email: m.slade@iop.kcl.ac.uk

\section{Funding}

This project was funded by the National Institute for Health Research Service Delivery and Organisation programme (project number 08/1304/075).

\section{Acknowledgements}

This study was undertaken in the context of the NIHR Specialist Mental Health Biomedica Research Centre at the Institute of Psychiatry, King's College London and the South London and Maudsley NHS Foundation Trust. The study was supported by the Mental Health Research Network (MHRN) and associated with the MHRN acute care group (convenor S.J.). The views expressed in this paper are those of the authors and not necessarily those of the NHS, the NIHR or the Department of Health.

\section{References}

1 Jepson R, Di Blasi Z, Wright K, ter Riet G. Scoping Review of the Effectiveness of Mental Health Services. University of York, 2001.

2 Mind. Ward Watch. Mind's Campaign to Improve Hospital Conditions for Mental Health Patients. Mind, 2004.

3 Rose D. Users' Voices: The Perspectives of Mental Health Service Users on Community and Hospital Care. Sainsbury Centre for Mental Health, 2001.

4 Lloyd-Evans B, Slade M, Jagielska D, Johnson S. Residential alternatives to acute psychiatric hospital admission: systematic review. Br J Psychiatry 2009; 195: 109-17.

5 Johnson S, Gilburt H, Lloyd-Evans B, Osborn DPJ, Boardman J, Leese M, et al In-patient and residential alternatives to standard acute psychiatric wards in England. Br J Psychiatry 2009; 194: 456-63.

6 Johnson S, Lloyd-Evans B, Morant N, Gilburt H, Shepherd G, Slade M, et al. Alternatives to standard acute in-patient care in England: roles and populations served. Br J Psychiatry 2010 (suppl 53): S6-13.

7 Wing JK, Beevor AS, Curtis RH, Park SB, Hadden S, Burns A. Health of the Nation Outcome Scales (HoNOS). Research and development. Br J Psychiatry 1998; 172: 11-8.

8 Jones SH, Thornicroft G, Coffey M, Dunn G. A brief mental health outcome scale - reliability and validity of the Global Assessment of Functioning (GAF). Br J Psychiatry 1995; 166: 654-9.

9 Salvi G, Leese M, Slade M. Routine use of mental health outcome assessments: choosing the measure. Br J Psychiatry 2005; 186: 146-52.

10 Department of Health. Reference Costs 2006. Department of Health, 2007.

11 Parabiaghi A, Barbato A, D'Avanzo B, Erlicher A, Lora A. Assessing reliable and clinically significant change on Health of the Nation Outcome Scales: method for displaying longitudinal data. Aust N Z J Psychiatry 2005; 39: 719-25.

12 Fenwick E, Byford S. A guide to cost-effectiveness acceptability curves. Br J Psychiatry 2005; 187: 106-8.
13 Lloyd-Evans B, Johnson S, Morant N, Gilburt H, Osborn DPJ, Jagielska D, et al. Alternatives to standard acute in-patient care in England: differences in content of care and staff-patient contact. Br J Psychiatry 2010 (suppl 53): s46-51.

14 Australian Mental Health Outcomes and Classification Network. Adult National Outcomes and Casemix Collection Standard Reports, version 1.1. AMHOCN, 2005

15 Trauer T, Eagar K, Mellsop G. Ethnicity, deprivation and mental health outcomes. Austr Health Rev 2006; 30: 310-21.

16 Melvin M, Hall P, Bienek E. Redesigning acute mental health services: an audit into the quality of inpatient care before and after service redesign in Grampian. J Ment Health 2005; 12: 733-8.

17 Howard L, Flach S, Leese M, Byford S, Killaspy H, Cole L, et al. Effectiveness and cost-effectiveness of admissions to women's crisis houses compared with traditional psychiatric wards: pilot patient-preference randomised controlled trial. Br J Psychiatry 2010 (suppl 53): s32-40.

18 Howard LM, Leese $\mathrm{M}$, Byford S, Killaspy $\mathrm{H}$, Cole L, Lawlor $\mathrm{C}$, et al. Methodological challenges in evaluating the effectiveness of women's crisis houses compared with psychiatric wards; findings from a pilot patient preference RCT. J Nerv Ment Dis 2009; 197: 722-7.

19 College Centre for Quality Improvement. Healthcare Commission: National Audit of Violence 2006-7. Final Report - Working Age Adult Services. Royal College of Psychiatrists, 2008.

20 Osborn DPJ, Lloyd-Evans B, Johnson S, Gilburt H, Byford S, Leese M, et al. Residential alternatives to acute in-patient care in England: satisfaction, ward atmosphere and service user experiences. Br J Psychiatry 2010 (suppl 53): s41-5.

21 Gilburt H, Slade M, Rose D, Lloyd-Evans B, Johnson S, Osborn DPJ. Service users' experiences of residential alternatives to standard acute wards: qualitative study of similarities and differences. Br J Psychiatry 2010 (suppl 53): s26-31.

22 Campbell NC, Murray E, Darbyshire J, Emery J, Farmer A, Griffiths F, et al. Designing and evaluating complex interventions to improve health care. BMJ 2007; 334: 455-9.

23 Pawson R, Tilley N. Realistic Evaluation. Sage, 1997.

24 McCrone $\mathrm{P}$, Johnson S, Nolan F, Pilling S, Sandor A, Hoult J, et al. Economic evaluation of a crisis resolution service: a randomised controlled trial. Epidemiol Psichiatr Soc 2009; 18: 54-8.

25 Plovnick RM. Innovations in the utilization of health information technology in psychiatric services. Epidemiol Psichiatr Soc 2009; 18: 5-11.

26 Healthcare Commission. Count Me In 2007: Results of the 2007 National Census of Inpatients in Mental Health and Learning Disability Services in England and Wales. Commission for Healthcare Audit and Inspection, 2007.

27 Johnson S, Nolan F, Pilling S, Sandor A, Hoult J, McKenzie N, et al. Randomised controlled trial of acute mental health care by a crisis resolution team: the north Islington crisis study. BMJ 2005; 331: 599.

28 Glover G, Arts G, Babu KS. Crisis resolution/home treatment teams and psychiatric admission rates in England. $B r J$ Psychiatry 2006; 189: 441-5.

29 Byford S, Sharac J, Lloyd-Evans B, Gilburt H, Osborn DPJ, Leese M, et al. Alternatives to standard acute in-patient care in England: readmissions, service use and cost after discharge. Br J Psychiatry 2010 (suppl 53): s20-5.

30 Priebe S, Katsakou C, Amos T, Leese M, Morriss R, Rose D, et al. Patients' views and readmissions 1 year after involuntary hospitalisation. $\mathrm{Br} J$ Psychiatry 2009; 194: 49-54.

31 Mental Health Act Commission. Risk, Rights and Recovery. Twelfth Biennial Report 2005-2007. TSO (The Stationery Office), 2008

32 Royal College of Psychiatrists' Policy Unit. Fair Deal for Mental Health. Royal College of Psychiatrists, 2008.

33 Slade M. Personal Recovery and Mental IIIness. A Guide for Mental Health Professionals. Cambridge University Press, 2009.

34 Care Services Improvement Partnership, Care. Laying the Foundations for Better Acute Mental Healthcare. A Service Redesign and Capital Investment Workbook. TSO (The Stationery Office), 2008.

35 Healthcare Commission. The Pathway to Recovery. A Review of NHS Acute Inpatient Mental Health Services. Healthcare Commission, 2007. 